\title{
Transplanted Sympathetic Neurons from Old Rats Survive in the Anterior Eye Chamber: A Histochemical and Electron Microscopic Study
}

\author{
Jaana Suhonen and Antti Hervonen \\ Laboratory of Gerontology, Department of Public Health, University of Tampere \\ Medical School and Tampere Brain Research Center \\ P.O. Box 607, SF-33101 Tampere, Finland
}

\section{SUMMARY}

The purpose of this study was to investigate the viability and ultrastructural characteristics of intraocular superior cervical ganglion (SCG) grafts from young (3 months), aged ( 24 months) and very old (36 months) rats after short-term (1 month) grafting. The formaldehyde-induced fluorescence (FIF) technique for histochemical demonstration of catecholamines was used to indicate the functionality of transplanted neurons. Ultrastructural changes in grafts were demonstrated by electron microscopy. Four weeks after transplantation, catecholamine histofluorescence in young transplants was almost as strong as in the intact ganglia, while aged and very old grafts showed decreased fluorescence and contained a marked accumulation of autofluorescent lipopigment bodies. Catecholamine histofluorescence showed a decrease in neuronal density of $47 \%, 59 \%$ and $68 \%$ in young, aged and very old grafted ganglia, respectively. The shape of most of the transplanted neurons did not differ from that in the intact ganglia, but the average diameter of neurons was decreased after grafting. In electron microscopy, both neurons with normal in vivo fine structure and neurons showing some abnormal cytological alterations were seen in each age group of the transplants. The most prominent feature after grafting was the

Reprint address:

Dr. Jaana Suhonen

University of Tampere

Department of Public Health

Laboratory of Gerontology

P.O. Box 607, SF-33101 Tampere, Finland accumulation of different types of lipopigment bodies in the perikarya of neurons. The organization of the rough endoplasmic reticulum was more irregular in transplanted neurons than in intact neurons. In addition, the amount of neurofilament aggregates increased and some mitochondria were swollen in neurons after transplantation. These results suggest that young sympathetic ganglion tissue survives rather well after transplantation into the anterior eye chamber, while in the aged sympathetic ganglion implants the survival rate is poorer. However, aged and very old SCG grafts were shown to contain and continue to produce noradrenaline, indicating that sympathetic neurons maintain their plasticity and regenerative ability in advanced age. Catecholamine histofluorescence and fine structural changes in the cell structure of grafted sympathetic neurons may indicate an accelerated aging process induced by the transplantation procedure.

\section{KEY WORDS}

superior cervical ganglion, transplantation, electron microscopy, catecholamine histofluorescence, aging, rat

\section{INTRODUCTION}

Neural grafting is a useful method for investigating the degeneration and regeneration of the central and peripheral nervous systems of mammals. The intraocular grafting model $/ 22 /$ provides a unique opportunity for studies of 
isolated areas of the nervous system in a controlled in vivo environment. Earlier papers $15,10,27,33,34 /$ have shown that adrenergic embryonic, adult and aged neural grafts survive in the anterior chamber of the eye. Most of the data available on sympathetic transplants are based on studies with fetal or young experimental animals $/ 27,31 /$. So far little attention has been paid to the effect of aging on the survival of grafted neural tissue /34/. The aging process involves a decline in function or even loss of selected neural elements in the nervous system. Neuronal implantation provides an interesting new approach to the analysis of the cellular events underlying age-related functional impairments in experimental animals. On the other hand, most neurodegenerative diseases affect aging neurons. The age of many patients suffering from neurodegenerative diseases, such as Parkinson's disease, makes the evaluation of older tissue relevant.

In previous studies it has been clearly demonstrated that superior cervical ganglia (SCG) from embryonic, newborn and adult rats survive and form processes after intraocular $/ 28 /$ or intracerebral grafting $/ 2,23,29 /$. However, no studies have been published on the detailed ultrastructural properties of old sympathetic ganglia after transplantation. We have demonstrated in our earlier catecholamine histofluorescence studies that even sympathetic neurons from old donors can survive under suitable conditions $/ 35-38 /$. In this study our focus is on the histochemical and fine structural correlates of the functional plasticity of young and very old principal ganglion cells after short-term intraocular transplantation.

\section{MATERIAL AND METHODS}

\section{Animals}

A total of 54 male albino Wistar rats were used. The rats were aged three $(\mathrm{n}=38,200-250 \mathrm{~g}), 24$ $(\mathrm{n}=8,300-350 \mathrm{~g})$ and $36(\mathrm{n}=8,350-400 \mathrm{~g})$ months. Three animals from each age-group served as donor animals and 30 of the young ( 3 month) animals were used as hosts. The rest of the animals were used as intact controls (Table 1). The rats were housed in standard laboratory facilities with a
TABLE 1

Number and age of animals

\begin{tabular}{llll}
\hline & & Number of Animals \\
\hline Age of animals & $n$ (donors) & $n$ (hosts) & $n$ (intacts) \\
\hline 3 months & 3 & 30 & 5 \\
24 months & 3 & 5 \\
36 months & 3 & 5 \\
\hline & & 5 & 5 \\
\hline
\end{tabular}

constant light-dark cycle, constant relative humidity $(40 \pm 10 \%)$ and temperature $\left(23 \pm 1^{\circ} \mathrm{C}\right)$. The aging animal colony was kept on $-20 \%$ caloric restriction to postpone age-related diseases.

\section{Transplantation procedure}

The animals were anesthetized with sodium pentobarbital (Mebunat $\$$, Orion, Helsinki, Finland, $30 \mathrm{mg} / \mathrm{kg}$, i.p.) and sodium midatzolam (Dormicum $\otimes$, Roche, Switzerland, $20 \mathrm{mg} / \mathrm{kg}$, i.p.). Buprenorphine (Temgesic $\otimes$, Reckitt and Colman Pharm., Hull, UK, $2 \mathrm{mg} / \mathrm{kg}$, s.c.) was used as analgetic. The superior cervical ganglia (SCG) were dissected out from donor rats and placed in sterile Minimum Essential Medium (GIBCO, Life Technologies Ltd., Paisley, Scotland). The connective tissue capsule and the pre- and postganglionic fibers were removed from the ganglia prior to grafting. The ganglion was cut into pieces measuring $0.5-1 \mathrm{~mm}$ in size and grafted to the anterior chamber of both eyes in the host. The intraocular transplantation technique used has been described in detail elsewhere $/ 20 \%$. In brief, the transplant pieces were inserted into the eye chamber through a slit opening in the cornea and placed at a lateral angle on the anterior surface of the host iris. Four weeks after transplantation, the animals were sacrificed under deep anesthesia. The left eye of each host animal was immersed in liquid nitrogen for fluorescence microscopy. Then, the host rats were fixed by perfusion of $3 \%$ 
glutaraldehyde for electron microscopy, and the right eye was dissected and postfixed with the same fixative for four hours. Superior cervical ganglia from intact control (3, 24 and 36 months) animals were fixed and processed in the same way as the transplanted tissues (Table 1).

The vascularization and size of the transplants and the status of the eyes' anterior chambers were monitored (at time of implantation, one and four weeks postgrafting) through the cornea using a stereomicroscope with camera.

\section{Fluorescence histochemistry}

The freshly frozen specimens were processed according to the formaldehyde-induced fluorescence (FIF) method /4/. Tissues were freezedried at $-40^{\circ} \mathrm{C}$ under $1.3 \times 10^{-3} \mathrm{~Pa}$ pressure for 7 days, exposed to formaldehyde vapor at $+60^{\circ} \mathrm{C}$ for $60 \mathrm{~min}$, and embedded in paraffin in vacuo. The specimens were sectioned serially at $10 \mu \mathrm{m}$ and then coverslipped using liquid paraffin. The sections were viewed and photographed using an Olympus Vanox-T fluorescence microscope (Olympus, Tokyo, Japan) with a special set of filters for catecholamine fluorescence.

\section{Electron microscopy}

The glutaraldehyde-fixed tissues were postfixed with $1 \% \mathrm{OsO}_{4}$ buffered with $0.1 \mathrm{M}$ phosphate at $\mathrm{pH} 7.3 \mathrm{in}+4^{\circ} \mathrm{C}$ for $1 \mathrm{~h}$. Ultrathin sections of the Epon-embedded specimens were cut with an LKB III ultramicrotome using a diamond knife. The specimens were stained on grids with uranyl acetate. A Jeol Jem $100 \mathrm{C}$ electron microscope was used for viewing and photography.

\section{Morphometry}

The density of neurons and the mean diameter of the neuronal somata were measured in randomly selected areas of SCGs before the grafting operation and at one month postgrafting from the fluorescence samples using a Java (Jandel Scientific, Corte Madera, CA) image analysis system set up with an Olympus Vanox-T microscope and a MikroMikko AT computer (Nokia, Finland). All the surviving ganglion cells from transplants and intact ganglion cells from each group were counted in every 10th section. In addition, the diameters (average for each cell of the major and minor axes) of grafted and intact neurons were measured from the same sections. Table 2 summarizes the cell sizes of the intact and grafted SCG cells and Figure 12 the numbers of grafted neurons counted compared with intact ganglia of the same age. The numerical data were analyzed using Student's two-way t-test.

\section{RESULTS}

\section{Fluorescence microscopy}

\section{Intact sympathetic neurons}

The intact SCG from young and aged rats contained postganglionic sympathetic neurons of varying sizes with greenish blue fluorescent cytoplasm. Strongly fluorescent catecholaminergic fibers were observed among these principal neurons. In the 3 month-old SCG, a few autofluorescent lipopigment granules were found in principal neurons (Fig. 1a). At 24 and 36 months, most of the neurons contained yellowish lipopigment autofluorescence in SCG cells (Figs. $2 \mathrm{a}, 3 \mathrm{a})$. The average diameters of the neurons were $26.1 \pm 1.0 \mu \mathrm{m}$ (mean $\pm \mathrm{SD}$ ) in the 3 month-old rats, $27.4 \pm 0.9 \mu \mathrm{m}$ in 24 month-old rats and $28.5 \pm 0.7$ $\mu \mathrm{m}$ in 36 month-old rats (Table 2). The difference between young and aged and very old neurons was statistically significant at $p<0.01$.

\section{Transplanted sympathetic neurons}

Four weeks after intraocular transplantation, $95 \%$ of the rats $(n=30)$ had surviving transplants on the surfaces of the host irises in both eyes. In general, all ganglia transplants demonstrated a decrease in size after the first week postgrafting. Thereafter, the size of the ganglia transplants remained stable. The first blood vessels in grafts were observed one week postgrafting. There was no distinct difference in revascularization between young and aged grafts.

Young grafts ( 3 months) showed catecholamine histofluorescence comparable to that in intact 

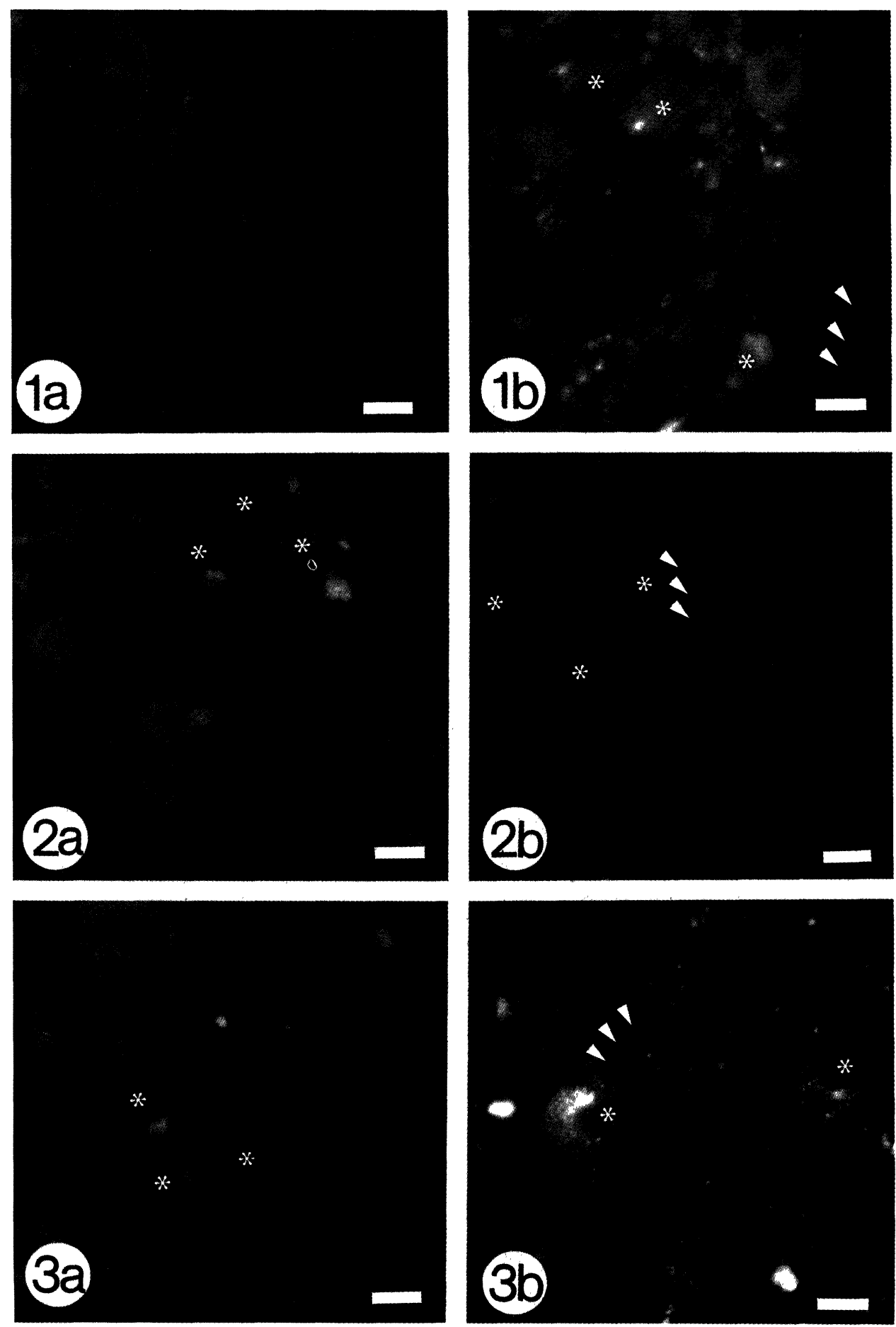

Figs. 1, 2, and 3: Fluorescence micrographs of intact sympathetic ganglia from young (3 mo) (1a), aged (24 mo) (2a) and very old (36 mo) (3a) rats. Aged and very old ganglion cells contain some yellow lipopigment autofluorescence (*). Four weeks after transplantation the ganglion cells show a strong catecholamine histofluorescence in young animals (1b) and a marked lipopigment autofluorescence $\left({ }^{*}\right)$ in aged (2b) and very old (3b) neurons. The short catecholamine fluorescent nerve fibers (arrowheads) are seen in the transplants (1b,2b,3b). Bars $15 \mu \mathrm{m}$. 
TABLE 2

Summary of the measured averaged diameters of intact and grafted ganglion cells

\begin{tabular}{|c|c|c|}
\hline Age of animals & $\begin{array}{c}\text { Intact }{ }_{\mu \mathrm{m}}^{\text {ganglion }} \\
\mu\end{array}$ & $\begin{array}{c}\text { Grafted ganglion } \\
\mu \mathrm{m}\end{array}$ \\
\hline 3 months & $26.1 \pm 1.1$ & $25.1 \pm 0.9$ \\
\hline 24 months & $27.4 \pm 0.9^{\mathrm{a}}$ & $25.2 \pm 0.7^{\mathrm{c}}$ \\
\hline 36 months & $28.5 \pm 0.7^{b}$ & $26.2 \pm 0.9^{d}$ \\
\hline
\end{tabular}

The diameters $(\mu \mathrm{m})$ are expressed as mean \pm SD

Postgrafting time one month.

$\mathrm{ab}_{\mathrm{p}}<0.01$ compared with the intact 3 months old rat

$c_{p}<0.01$ compared with the intact 24 months old rat

$d_{p}<0.01$ compared with the intact 36 months old rat.

ganglia. The number of lipopigment granules was increased in transplanted neurons (Fig. 1b). The number of grafted neurons was decreased by about $57 \%$ compared with the intact ganglia of the same age (Fig. 12). Almost all of the transplanted aged (24 months) and very old (36 months) neurons contained catecholamine histofluorescence and showed a marked accumulation of lipopigment bodies (Figs. 2b,3b). In addition, some transplanted principal ganglion cells showed only yellowish lipofuscin autofluorescence in clustered granules and no visible cytoplasmic catecholaminergic fluorescence (Fig. 2b). In most of the transplants the neurons were scattered throughout the graft, but some areas showed almost complete loss of neurons in the very old grafts. The density of neurons was clearly decreased in old grafts, by $59 \%$ in the aged and by $68 \%$ in the very old transplants compared with the intact ganglia of the same age (Fig. 12). In all transplants there were some short fluorescent catecholaminergic fibers (Figs. 1b,2b,3b), but they did not clearly innervate the host iris.

The shape of most of the grafted neurons did not differ from that in the intact ganglia. The average diameter of the grafted neurons decreased from $26.1 \pm 1.0 \mu \mathrm{m}$ (mean \pm SD) to $25.1 \pm 0.9 \mu \mathrm{m}$ in young transplants, from $27.4 \pm 0.09 \mu \mathrm{m}$ to 25.2 $\pm 0.7 \mu \mathrm{m}$ in aged grafts and in very old grafts from $28.5 \pm 0.7 \mu \mathrm{m}$ to $26.2 \pm 0.9 \mu \mathrm{m}$ (Table 2). The diameter values showed a shift to smaller cells in the ganglion transplants of each age group. The difference between intact and grafted neurons was statistically significant in the aged and very old neurons $(p<0.01)$, but not in the young neurons $(p>0.05)$ (Table 2).

\section{Electron microscopy \\ Intact sympathetic neurons}

In young ( 3 months) intact rats the principal sympathetic neurons were usually round and all the typical neuronal cytoplasmic organelles were seen in the perikarya (Fig. 4a). The rough endoplasmic reticulum (RER) was aggregated in the form of Nissl substance and the Golgi apparatus was usually located perinuclearly. Lysosomal material was regularly found dispersed in the cytoplasm, and the first few lipofuscin pigment bodies could be observed in the perikarya of neurons (Fig. 4a). The principal neurons were partly surrounded by Schwann cells. These cells contained ellipsoid nuclei, which were smaller and denser than the nuclei of the neurons. The mitochondria of the Schwann cells were slightly larger and darker than those of the neurons.

In aged ( 24 months) and very old (36 months) rats no major changes were found in the cytoplasmic organelles (Figs. 5a,6a). The most prominent change with age was the accumulation of pigment bodies in principal neurons. The pigment bodies typically revealed three components: an electron-dense homogeneous matrix, electron-lucent vacuoles and highly osmiophilic granular inclusions (Figs. 5a,6a). The pigment bodies were dispersed homogeneously in younger animals, while in more aged animals they were usually in clumps perinuclearly. The amount of pigment bodies varied from neuron to neuron, and a few neuronic profiles without pigment were seen even in the most aged animals. However, the amount of pigment clearly increased with age. The ultrastructure of the pigment bodies found in Schwann cells was similar to that found in neurons. The amount of fibrillary material increased and the organization of the RER was random in aged rats 


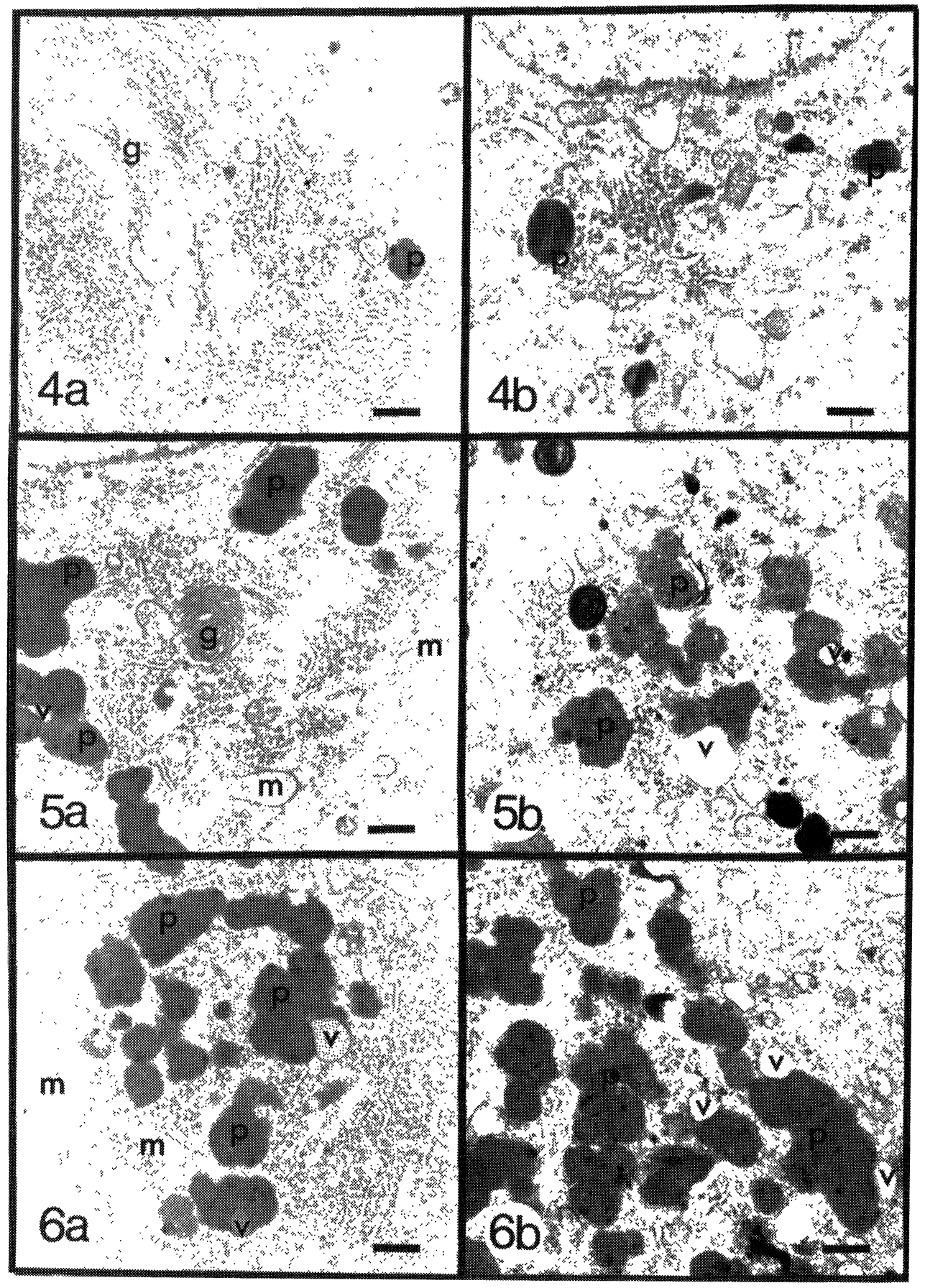

Figs. 4, 5 and 6: Electron micrographs of principal sympathetic ganglion cells from young (4a), aged (5a) and very old (6a) intact rats. Mitochondria $(\mathrm{m})$, Golgi apparatus $(\mathrm{g})$ and pigment bodies $(\mathrm{p})$ are seen in typical locations in the cytoplasm. The pigment bodies $(\mathrm{p})$ contain vacuoles $(\mathrm{v})$ and a homegeneous matrix $(\mathrm{p})$ within which some highly osmiophilic material is scattered. Four weeks postgrafting tranplanted ganglion cells $(\mathbf{4 b}, \mathbf{5 b}, \mathbf{6 b})$ show the same cytoplasmic organelles as in the normal intact neurons, but the organization of the rough endoplasmic reticulum (RER) is indefinite and the fibrillary material splits the RER. The number of pigment bodies (p) is increased in transplanted neurons. Bars $500 \mathrm{~nm}$. 
as compared with young animals. The amount of Golgi apparatus and mitochondria appeared to decrease with age.

\section{Transplanted sympathetic neurons}

Four weeks after transplantation, both neurons with normal in vivo fine structure and neurons showing some atypical cytological alterations were seen in each age group of the transplants. The grafted neurons classified as normal had a round, large nucleus, intact mitochondria and Golgi apparatus, regularly arranged neurofilaments and RER, and a varying number of lysosomes and pigment bodies. SCG cells made synaptic structures inside the graft, but these structures were not observed between grafted neurons and host iris tissue. Atypical cell structural changes were observed in each age group, but their number was clearly increased in very old transplants. The organization of the RER was indefinite and the fibrillary material split the RER. There were less typical Golgi-profiles in the aged transplants, and the number of mitochondria tended to decrease after grafting. The mitochondria showed some swelling in the transplants, but the cristea remained

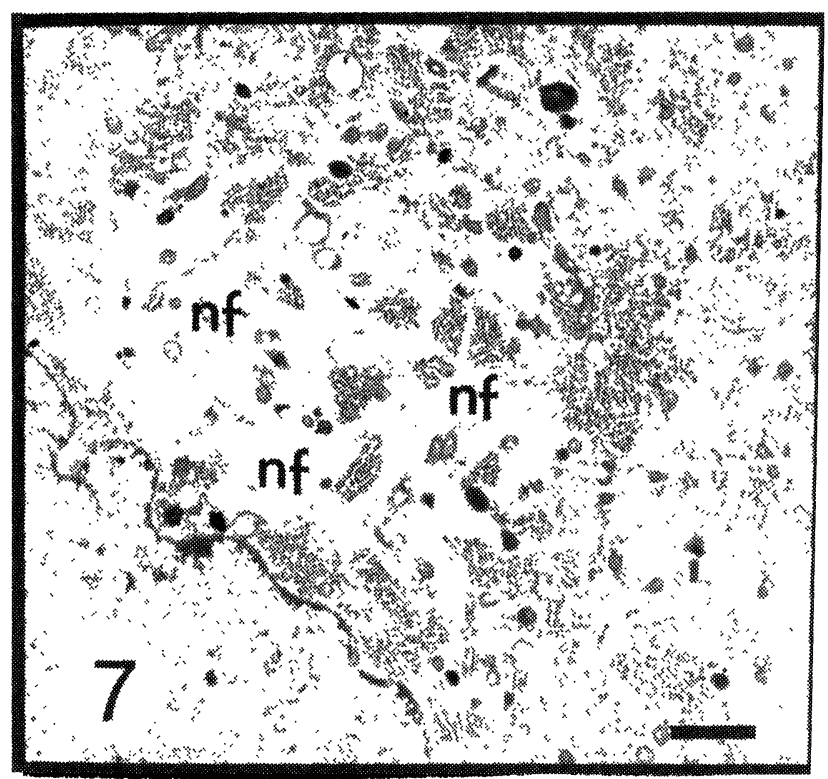

Fig. 7: A large neurofilament (nf) bundle in the perikarya of a neuron in a young transplant. Bar $2 \mu \mathrm{m}$. intact. The swollen mitochondria were usually located in the central region of the ganglion cell cytoplasm, where the Nissl substance had disappeared. The nuclear membranes of neurons were strongly invaginated (Figs. 8,10 ) in over $30 \%$ of the grafted neurons in all age groups.

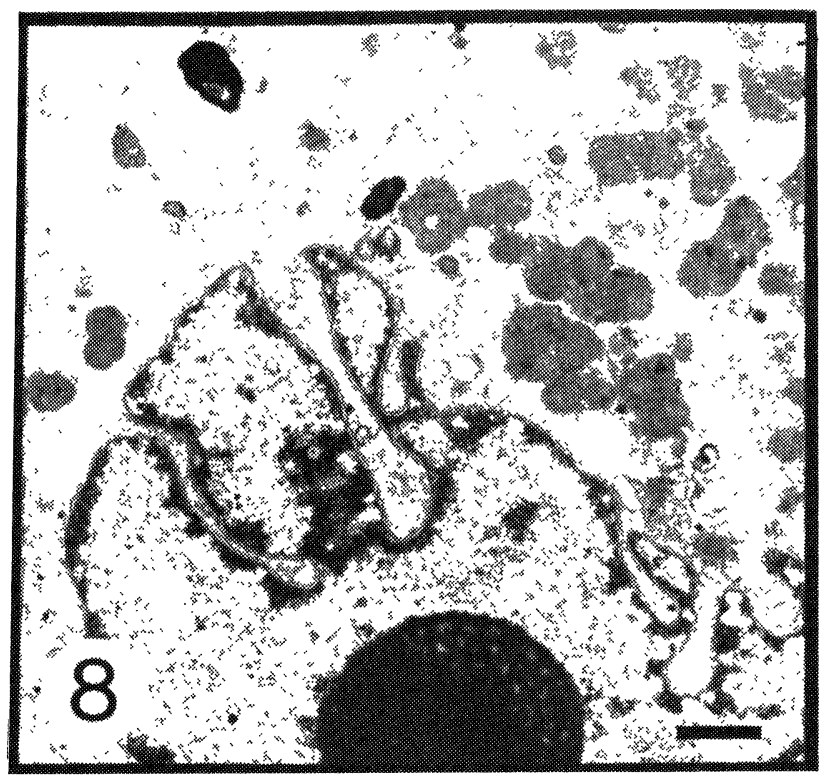

Fig. 8: Invagination of the nuclear membrane of an aged transplant. Bar $1 \mu \mathrm{m}$.

The most prominent change after transplantation was the accumulation of pigment bodies in the principal neurons. In aged transplants the pigment bodies appeared in clusters perinuclearly, whereas in younger transplants they were evenly dispersed. The number of pigment bodies varied from neuron to neuron, but neuronal profiles without pigment were not seen in the grafts. The pigment bodies consisted of three components: an electron-dense homogeneous matrix, electron-lucent vacuoles and some highly osmiophilic granular material (Figs. $4 \mathrm{~b}, 5 \mathrm{~b}, 6 \mathrm{~b})$. The relative amounts of these components varied but the number of electrondense bodies with vacuoles increased with age in transplants. In addition, some electron-dense components of the pigment bodies contained lamellar structures that in most cases were clearly arranged in rows (Figs. 4b, 9), whereas in intact neurons the lamellar structures usually showed no 


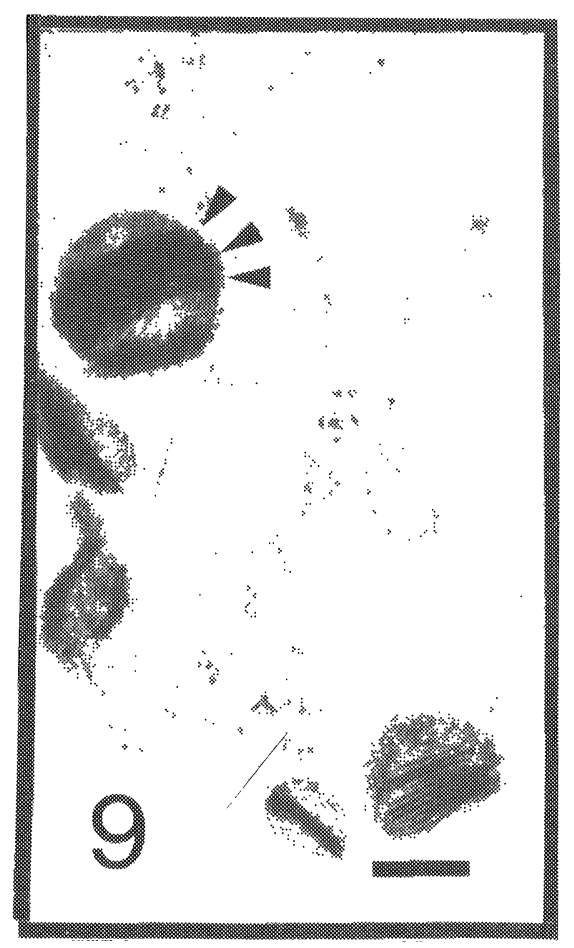

Fig. 9: The electron-dense components of pigment bodies containing lamellar figures clcarly arranged in rows (arrowheads) in young grafts. Bar $200 \mathrm{~nm}$. order. Furthermore, a few aged transplanted neurons showed massive pigment accumulations (Figs. 10, 11). In addition to classic age pigment bodies, these neurons displayed pigment bodies consisting of big electron-lucent vacuoles with clusters of electron-dense material and some homogeneous large pigment inclusions (Figs. 10, 11). The size of these big vacuoles $(1.0-2.0 \mu \mathrm{m})$ was greater than that of classic lipofuscin pigment bodies $(0.5-1.0 \mu \mathrm{m})$. These neurons also showed lamellar myelin bodies (Figs. 10, 11). These alterations were not observed in intact neurons. Finally, neuronfilament aggregates were present in a few of the youngest transplants, but their number increased with age. Twenty percent of the very old grafted SCG neurons showed neurofilament aggregates which were frequently localized around the nucleus (Fig. 7).

\section{DISCUSSION}

Using the dual methods of catecholamine histofluorescence and electron microscopy, we investigated the functionality and ultrastructural changes occurring in sympathetic neurons from

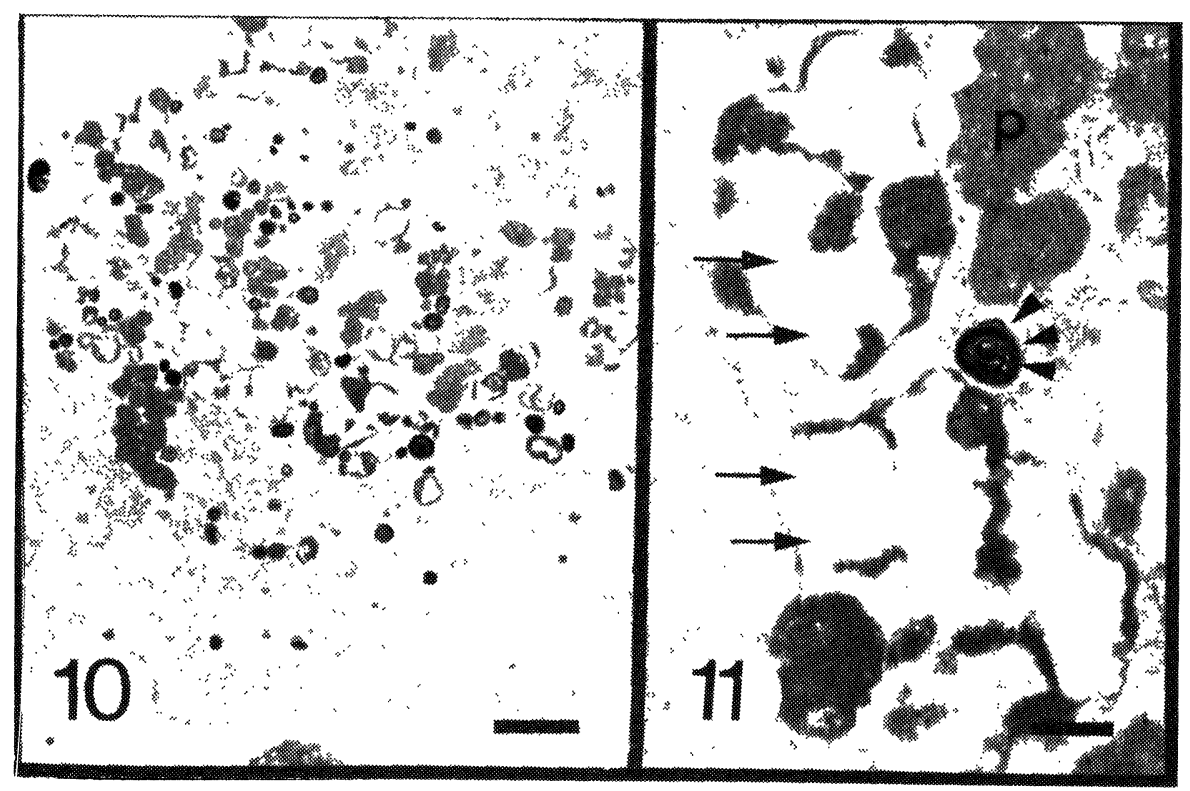

Fig. 10 and 11: A massive pigment accumulation in the perikarya of a neuron in an aged transplant (10). Bar $3 \mu \mathrm{m}$. Larger magnification of this area (11) shows large electron-lucent vacuoles (arrows), myelin bodies (arrowheads) and typical pigment bodies (p). Bar $500 \mathrm{~nm}$. 


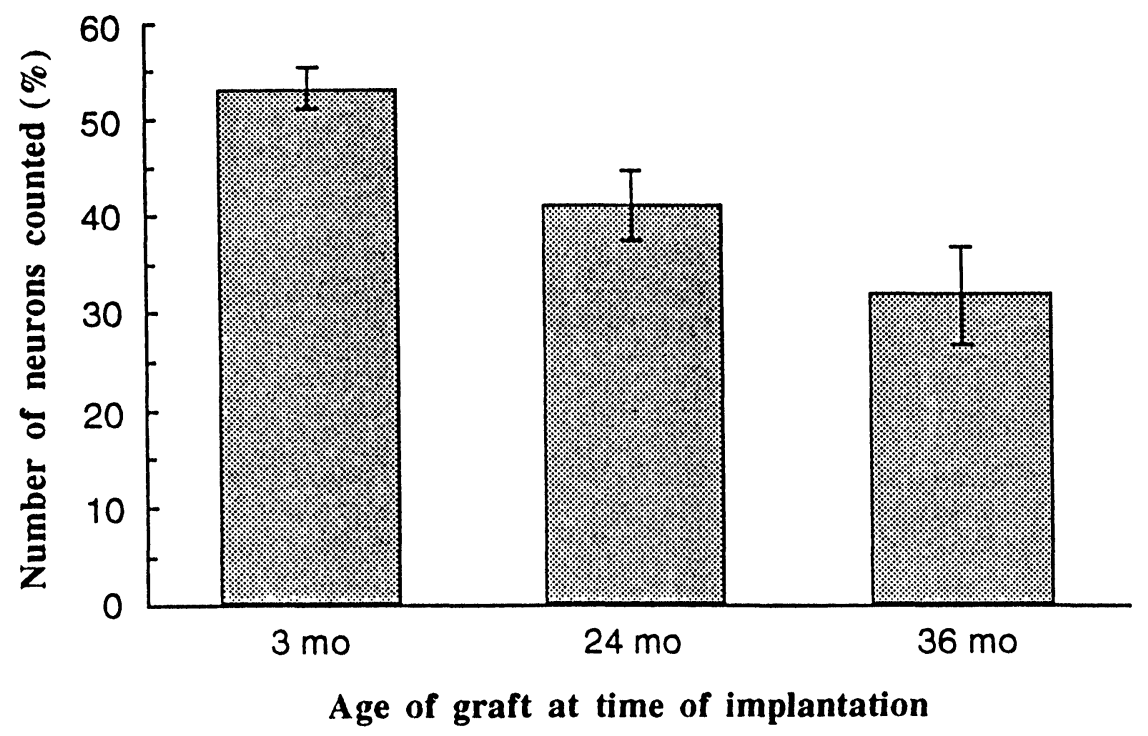

Fig. 12: The graph summarizes the densities of grafted neurons of different ages (number of neurons counted \%). Comparisons are made between intact ganglion cells and ganglion cells one month after intraocular grafting. Standard deviations are given by error bars.

young, aged and very old rats after short-term intraocular transplantation. The catecholamine fluorescence findings showed that even very aged adrenergic neurons survived the transplantation procedure. In qualitative terms the ultrastructure of the surviving sympathetic neurons showed no exceptional neuropathology after grafting. The basic cytoplasmic components in the transplants were similar to those found in intact aging sympathetic neurons, but fewer in number.

The formaldehyde-induced fluorescence (FIF) method demonstrates catecholamines in tissues under fluorescence microscopy $/ 4 /$. As observed earlier $/ 8,9,21,22 /$, the sympathetic ganglia contain catecholamine cells with pigment bodies. The number of lipopigment granules was found to increase with age in neurons; this is consistent with earlier findings. In transplanted neurons, catecholamine histofluorescence decreased following transplantation, and the number of autofluorescent pigment bodies increased. These changes were most prominent in the older age groups of grafts. The density of neurons clearly decreased from the young to the aged grafts, indicating progressive degeneration in aging transplants. In addition, only a few grafted neurons grew nerve fibers. One possible explanation for the low level of regrowth is that the recipient rats were not sympathectomized before transplantation. It is generally known that denervation of host SCG before intraocular transplantation improves the viability of grafted neurons and also induces regrowth of nerve fibers. In conclusion, the fluorescent microscopic results of this work suggest that transplanted young and old SCGs contain and continue to produce noradrenaline, which is responsible for the catecholamine-specific fluorescence.

The accumulation of fluorescent lipopigment in postmitotic cells is one of the basic - and one of the most commonly reported $/ 24,29,32 /$ - changes occurring with aging. Although the causes of lipopigment formation are still a matter of controversy, it is widely accepted that the accumulation of lipopigments reflects the free radical-induced peroxidation of lipids and proteins that takes place in postmitotic cells during aging and under oxidative stress $/ 3,6,31 /$. An alternative theory suggests that an impairment of the proteolytic enzyme activities of cells leads to the accumulation of lipopigments $/ 39,13 /$. These two mechanisms need not be contradictory, since free 
radical-induced inactivation of the degenerative enzymes may result in a defective degradative function of the cells $/ 6,31 /$. Furthermore, recent studies on the experimental production of lipopigment suggest a role for impaired protease function in rapid pigment accumulation /12,14/, whereas pigment formation over longer periods of time would appear to be due to the lack of essential antioxidants $/ 17 /$. In this study autofluorescent lipopigmentation increased after grafting, especially in aged and very old grafted neurons. Viewed with electron microscopy, lipopigment bodies consisted of big electron-lucent vacuoles and some large homogeneous pigment inclusions in addition to classic lipopigment. Similar pigment bodies are found in neurons after treatment with leupetin, a protease inhibitor $/ 13 /$ and in cultured aged sympathetic ganglion cells $/ 17,18 /$. These results suggest that pigment formation in transplanted peripheral sympathetic neurons may be explained by the altered function of lysosomal protease together with increased lipid peroxidation. The time-related linear accumulation of pigment in neurons thus serves as a useful model for studying intrinsic and environmental factors detrimental to the neuron.

A number of papers $/ 9,16,25 /$ have described the fine structural changes occurring in the sympathetic neurons of young and aged rats. In the present study, the ultrastructure of intact neurons in the superior cervical ganglia of young and aged animals did not differ from that found in earlier studies /9/. Principal ganglion cell bodies have been reported to contain distended perikaryal mitochondria $/ 25 /$, to show irregularity, disarrangement and dilatation of the rough endoplasmic reticulum and Golgi apparatus $/ 25 /$, and to show an increased somal area /21/. Many of the features of transplanted neurons shown here under electron microscopy are similar to the findings in intact adrenergic neurons in previous studies $/ 7,9 /$. The most prominent changes at the fine structural level in transplanted neurons were the increased accumulation of age pigment, the increase in the amount of neurofilament aggregates, and the reduction of rough endoplasmic roticulum after grafting. There was a moderate increase in the neurofilament content of aged and very old transplanted neurons. The amount of neurofilament aggregates varied from neuron to neuron, but it was usually seen in the same neurons that had increased pigment accumulation. According to previous studies $/ 1,26 /$ the number of neurofilaments in neurons increases in Wallerian degeneration and in certain neurodegenerative diseases such as Alzheimer's $/ 1,26 /$. The accumulation of neurofilaments may reflect failure to export the cytoskeletal material to the axon at the cell level in transplanted sympathetic neurons, and it may mean the commencement of cell death.

In conclusion, these results suggest that young sympathetic ganglion tissues survive rather well after transplantation into the anterior eye chamber, while in very aged sympathetic ganglion implants the survival rate is poorer. However, aged and very old SCG grafts contained and continued to produce noradrenaline, indicating that sympathetic neurons maintain their plasticity and regenerative ability in advanced age. Catecholamine histofluorescence and fine structural changes in the cell structure of grafted sympathetic neurons may indicate an accelerated aging process induced by the transplantation procedure.

\section{REFERENCES}

1. Barron KD, Dentinger MP, Nelson LR, Mincy JE. Ultrastructure of axonal reaction in red nucleus of cat. J Neuropathol Exp Neurol 1975; 34: 222-248.

2. Björklund A, Stenevi U. Experimental rinnervation of the rat hippocampus by grafted sympathetic ganglia. I. Axonal regeneration along the hippocampal fimbria. Brain Res 1977; 138: 259-270.

3. Donato $\mathrm{H}$. Lipid peroxidation, cross-linking reactions and aging. In: Sohal RS, ed, Age Pigments. Amsterdam: Elsevier, North Holland Biomedical Press, 1981; 63-81.

4. Eränkö $O$. The practical histochemical demonstration of catecholamines by formaldehyde-induced fluorescence. J R Microsc Soc 1967; 87: 259-276.

5. Granholm A-C, Gerhardt GA, Eriksdotter-Nilsson $M$, Bickford-Wimer PC, Palmer MR, Seiger Å, Olson L, Hoffer BJ. Age-related changes in cerebellar noradrenergic pre- and postsynaptic mechanisms: intrinsic vs extrinsic determinants evaluated with brain grafts in oculo. Brain Res 1987; 423: 71-78.

6. Harman D. Lipofuscin and ceroid formation: the cellular recycling system. Adv Exp MedBiol 1989; 266: 3-15. 
7. Helen P. Fine-structural and degenerative features in adult and aged human sympathetic ganglion cells. Mech Ageing Dev 1983; 23: 161-175.

8. Hervonen A, Vaalasti A, Partanen M, Kanerva L, Hervonen $\mathrm{H}$. Effects of ageing on the histochemically demonstrable catecholamines and acetylcholinesterase of human sympathetic ganglia. J Neurocytol 1978; 7: 11-23.

9. Hervonen A, Partanen M, Helen P, Koistinaho J, Alho $\mathrm{H}$, Baker DM, Johnson Jr JE, Santer RM. The sympathetic neurons as a model of neuronal aging. Neurohistochemistry: Modern Methods and Applications 1986; 569-586.

10. Hoffer B, Olson L, Seiger Å, Bloom FG. Formation of a functional adrenergic input to intraocular cerebellar grafts: ingrowth of inhibitory sympathetic fibers. J Neurobiol 1975; 6: 565-585.

11. Itakura TI, Kamei I, Nakai K, Naka Y, Nakakita K, Imai $\mathrm{H}$, Komai $\mathrm{N}$. Autotransplantation of superior cervical ganglion into the brain. J Neurosurg 1988; 68: 955-959.

12. Ivy GO, Gurd JW. A protease inhibitor model of lipofuscin formation. In: Zs- Nagy I, ed, Lipofuscin 1987: State of the Art. Amsterdam: Akademiai Kiado, Budapest and Elsevier, North Holland Biomedical Press 1988; 83-108.

13. Ivy GO, Wenzel J, Baydry M, Lynch G. Inhibitors of lysosomal enzymes: accumulation of lipofuscin-like dense bodies in the brain. Science 1984; 226: 985-988.

14. Ivy GO, Kanai S, Ohta M, Smith G, Sato Y, Kobayashi M, Kitani K. Lipofuscin-like substances accumulate rapidly in brain, retina and intestinal organs with cysteine protease inhibition. Adv Exp Med Biol 1989; 266: 31-47.

15. Katz ML, Robinson WG, Herman RL, Groome AB, Bieri JG. Lipofuscin accumulation resulting from senescence and vitamin $\mathrm{E}$ deficiency: spectral properties and tissue distribution. Mech Ageing Dev 1984; 25: 149-159.

16. Koistinaho J. Difference in the age-related accumulation of lipopigments in the adrenergic and noradrenergic peripheral neurons in the male rat. Gerontology 1986; 32: 300-307.

17. Koistanaho J, Hartikainen K, Hatanpää K, Hervonen A. Age pigments in different populations of peripheral neurons in vivo and in vitro. In: Porta EA, ed, Lipofuscin and Ceroid Pigments. New York: Plenum Press, 1990; 49-59.

18. Koistinaho J, Hatanpää $\mathrm{K}$, Hervonen A. Light and electron microscopic features of peripheral ganglion cells cultured from young and aged Wistar rats. Mech Ageing Dev 1991; 61: 23-32.

19. Mann DM, Yates PO. Lipoprotein pigments - Their relationship to ageing in the human nervous system. Brain 1974; 97: 489-498.

20. Olson L, Seiger A, Strömberg I. Intraocular transplantation in rodents. A detailed account of the procedure and examples of its use in neurobiology with special reference to brain tissue grafting. In: Fedoroff S, Hertz L, eds, Advances in Cellular Neurobiology. Vol 4. New York: Academic Press 1983; 407-442.

21. Partanen M, Santer RM, Hervonen A. The effect of ageing on the histochemically cemonstrable catecholamines in the hypogastric (main pelvic) ganglion of the rat. Histochemistry 1980; 12: 527-535.

22. Partanen M, Hervonen A, Rapoport SI. Microspectrofluorimetric quantitation of histochemistry demonstrable catecholamines in peripheral and brain catecholamine-containing neurons in male Fischer-344 rats at different ages. In: Giobini E, Filogamo G, Giacobini G, Vernadakis A, eds, The Aging Brain Cellular and Molecular Mechanisms of Aging in the Nervous System. Aging, Vol 20. New York: Raven Press, 1982; 161-172.

23. Rosenstein JM, Brightman MW. Some consequences of grafting autonomic ganglia to brain surfaces. In: Sladek Jr JR, Gash DM, eds, Neural Transplantation. New York: Plenum Press 1984; 423-443.

24. Samorajski T, Ordy JM, Keefe JR. The finestructure of lipofuscin age pigment in the nervous system of aged mice. J Cell Biol 1965; 26: 779-795.

25. Santer RM, Partanen M, Hervonen A. Glyoxylic acid fluorescence and ultrastructural studies of neurons in the coeliac-superior mesenteric ganglion of the aged rat. Cell Tissue Res 1980; 211: 475-483.

26. Schmidt RE. Pathology of the Sympathetic nervous system. In: Duckett S, ed, The Pathology of the Aging Human Nervous System. London: Lea \& Febiger 1991; 431-442.

27. Shetty AK, Banerjee R, Gopinath G, Tandon PN. fetal nigral grafts in the anterior eye chamber of adult rats: $A$ long-term morphological study. Exp Neurol 1991; 111: 106-114.

28. Stieg P, Strömberg I, Olson L. Effects of donor age on superior cervical ganglion transplants: eveluation by Falck-Hillarp histochemistry and immunocytochemistry. Exp Brain Res 1991; 85: 55-65.

29. Sohal RS, ed, Age Pigments. Amsterdam: Elsevier, North Holland, 1981

30. Sohal RS, Allen RG. Oxidative stress as a causal factor in differentiation and aging: a unifying hypothesis. Exp Gerontol 1990; 25: 499-522.

31. Sohal RS, Brunk U. Lipofuscin as an indicator of oxidative stress and aging. Adv Exp Medicine Biol 1990; 266: 17-29.

32. Strehler B. On the histochemistry and ultrastructure of age pigment. In: Strehler B, ed, Advances in Gerontology Research, Vol. 1. New York: Academic Press 1964.

33. Strömberg I, Ebendahl T, Seiger $\AA$, Olson L. Nerve fibre production by intraocular adrenal medullary grafts: Stimulation by nerve growth factor or sympathetic denervation of the host iris. Cell Tissue Res 1985; 241: 241-249. 
34. Strömberg I, Ebendal T. Aged adrenal medular tissue survives intraocular grafting, forms nerve fibres and responds to nerve growth factor. J Neurosci Res 1989; 23: $162-171$.

35. Suhonen J, Koistinaho J, Hervonen A. Viability of adrenal chromaffin cells in the surperior cervical ganglion of young adult and aged rats. Neurosci Let 1990a; 118: 215-218.

36. Suhonen J, Koistinaho J, Hervonen A. Survival of both young and aged sympathetic neurons in the adrenal cortex afterautotransplantation. Histochemistry 1990b; 94: 591-959.

37. Suhonen J, Koistinaho J, Hervonen A. Histochemistry of sympathetic neurons allotransplanted from young and aged mice to the submandibular gland. Exp Neurol 1991; 112: 104-111.
38. Suhonen J, Hervonen A. Sympathetic neurons outlive the original host after transplantation in the rat submandibular gland. Neurobiol Aging 1993; 14: 383387.

39. Wolfe LS, Gauthier S, Durham HD. Dolichols and phosphoryleted dolichols in the neuronal lipofuscinosis, other lysosomal storage diseases and Alzheimers disease. Induction of autolysosomes in fibroblasts. In: Zs-Nagy I, ed, Lipofuscin - 1987: State of the Art. Amsterdam: Akademiai Kiado, Budapest and Elsevier, North Holland Biomedical Press 1988; 389-411.

40. Zhou C-F, Lawrence JM, Morris RJ, Raisman G. Migration of host astrocytes into the superior cervical sympathetic ganglia autografted into the septal nuclei or choroid fissure of adult rats. Neuroscience 1986; 17 : 815-882. 

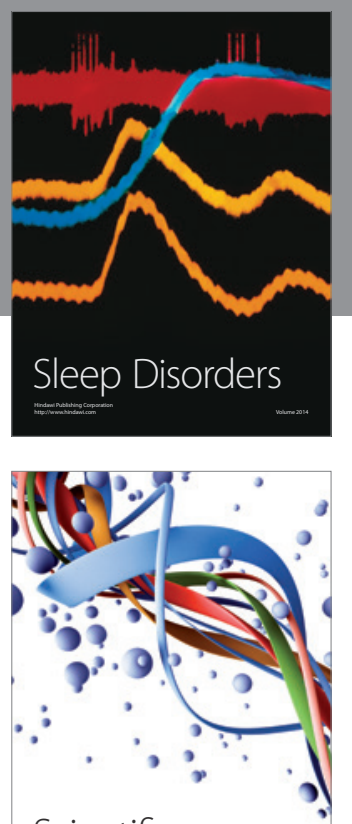

Scientifica
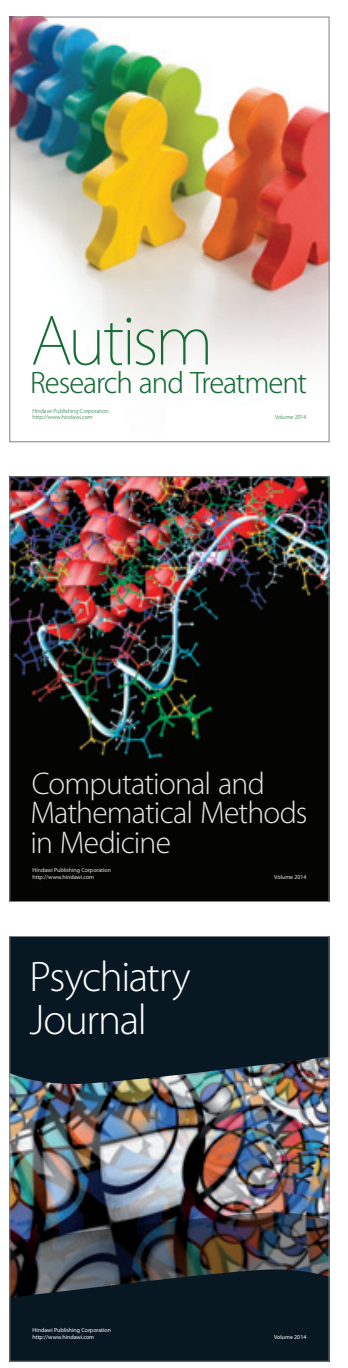
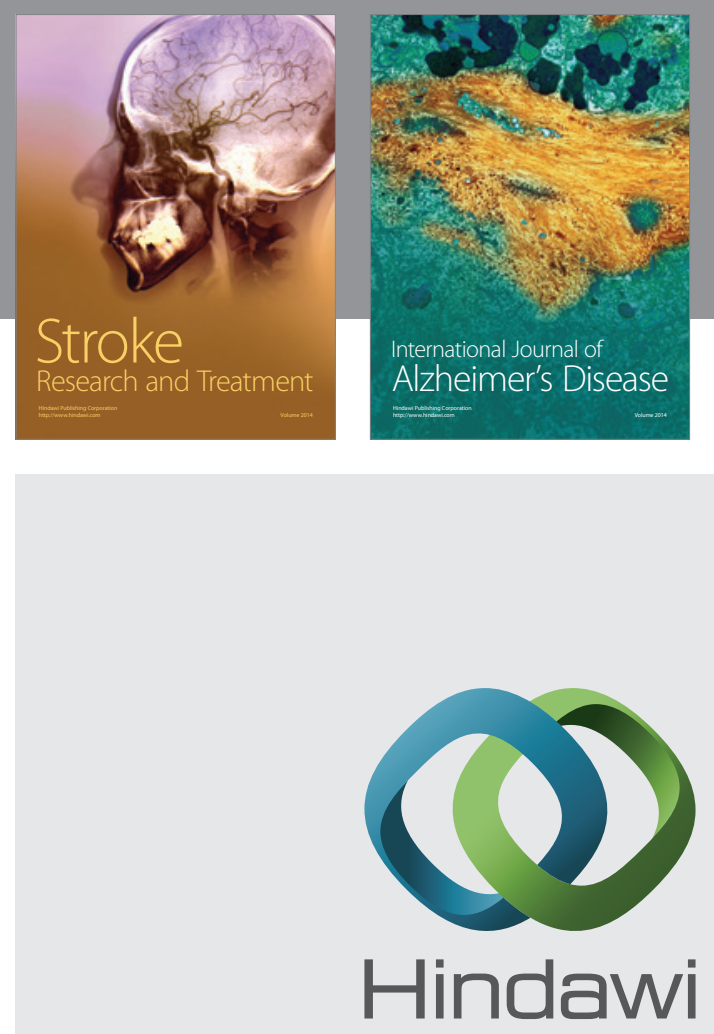

Submit your manuscripts at

http://www.hindawi.com
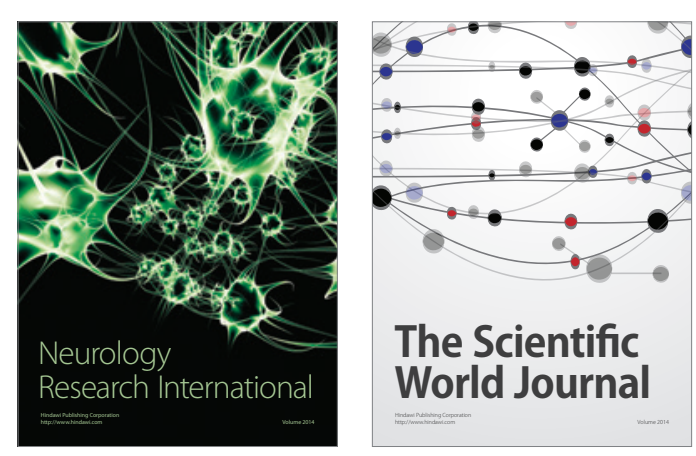

The Scientific World Journal

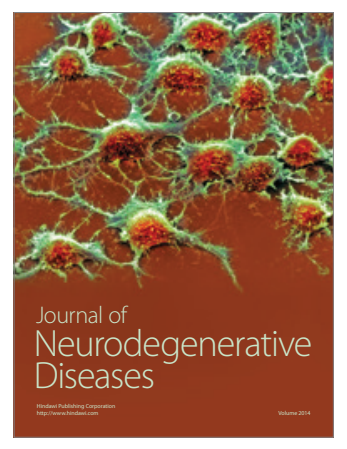

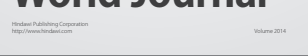

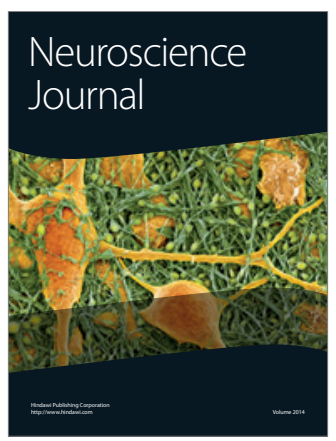

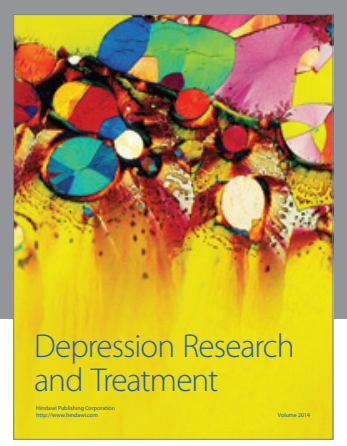
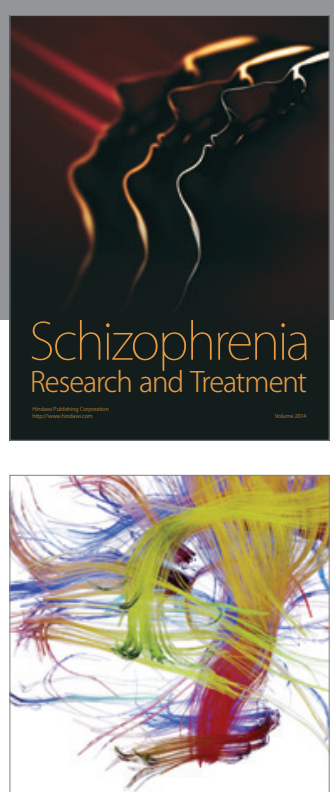

Brain Science

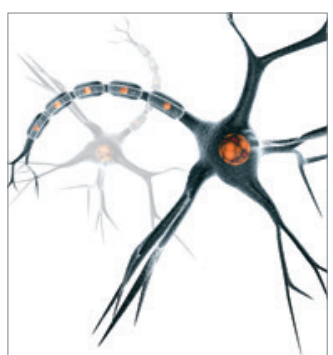

Neural Plasticity
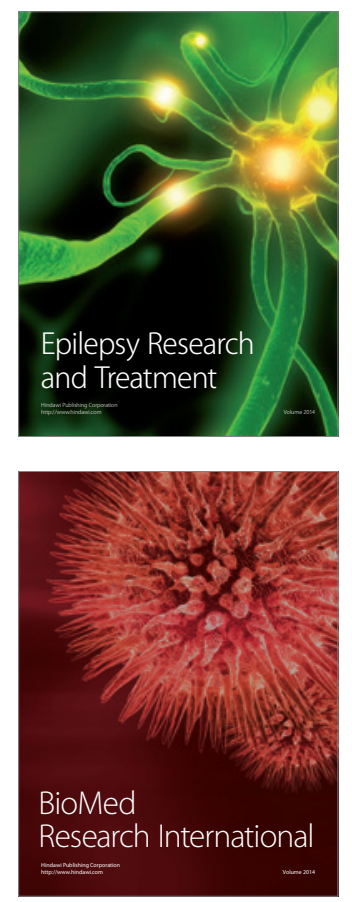

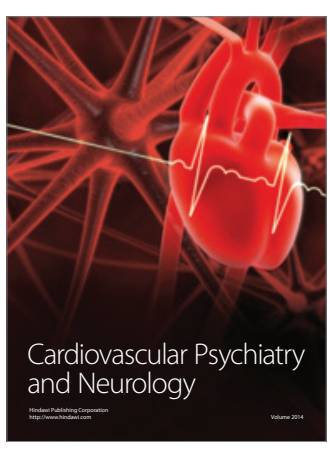

Parkinson's

Disease
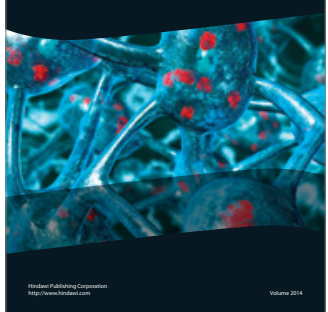